
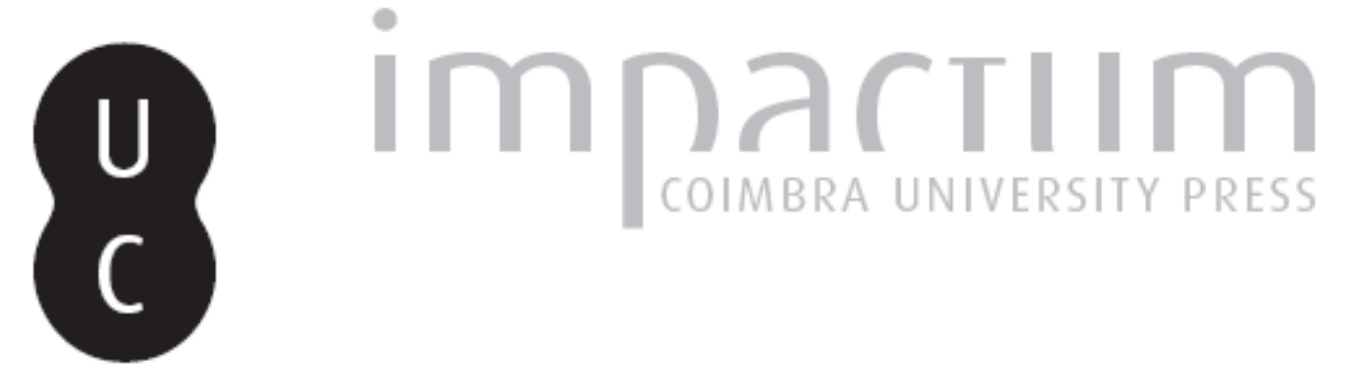

\title{
Encrucijadas dialécticas: Elenchos, dispositivos antierísticos y Filosofia megárica en las refutaciones sofísticas
}

Autor(es): $\quad$ Mársico, Claudia

Publicado por: Annablume Clássica; Imprensa da Universidade de Coimbra

URL persistente:

URI:http://hdl.handle.net/10316.2/36132

DOI:

DOI:http://dx.doi.org/10.14195/1984-249X_14_10

Accessed : $\quad$ 26-Apr-2023 13:32:54

A navegação consulta e descarregamento dos títulos inseridos nas Bibliotecas Digitais UC Digitalis, UC Pombalina e UC Impactum, pressupõem a aceitação plena e sem reservas dos Termos e Condições de Uso destas Bibliotecas Digitais, disponíveis em https://digitalis.uc.pt/pt-pt/termos.

Conforme exposto nos referidos Termos e Condições de Uso, o descarregamento de títulos de acesso restrito requer uma licença válida de autorização devendo o utilizador aceder ao(s) documento(s) a partir de um endereço de IP da instituição detentora da supramencionada licença.

Ao utilizador é apenas permitido o descarregamento para uso pessoal, pelo que o emprego do(s) título(s) descarregado(s) para outro fim, designadamente comercial, carece de autorização do respetivo autor ou editor da obra.

Na medida em que todas as obras da UC Digitalis se encontram protegidas pelo Código do Direito de Autor e Direitos Conexos e demais legislação aplicável, toda a cópia, parcial ou total, deste documento, nos casos em que é legalmente admitida, deverá conter ou fazer-se acompanhar por este aviso.

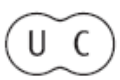




\section{4}

jan/jun

2015

issn 2179-4960 e-issn 1984-249-X
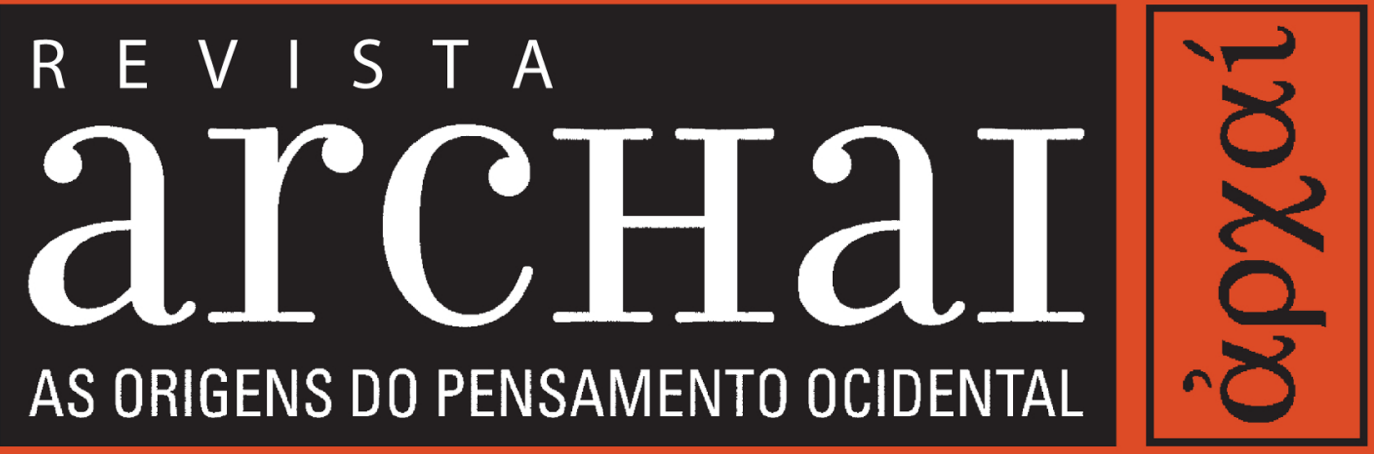

ARCHAI JOURNAL: ON THE ORIGINS OF WESTERN THOUGHT

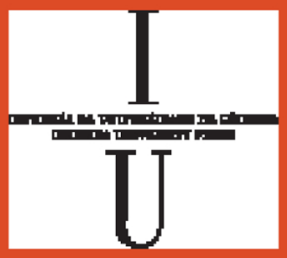

\section{archaI}

AS ORIGENS Do PENSAMENTO OCIDENTAL 
ENCRUCIJADAS DIALÉCTICAS: ELENCHOS, DISPOSITIVOS ANTIERÍSTICOS Y FILOSOFÍA MEGÁRICA EN LAS REFUTACIONES SOFÍSTICAS

\author{
Dialectic Crossroads: Elenchos, Antieristical Devices and Megaric
}

Philosophy in the Sophistical Refutations

MÁRSICO, C. (2014). Encrucijadas dialécticas: elenchos, dispositivos antierísticos y filosofía megárica en las Refutaciones sofísticas. Archai, n. 14, jan - jun, p. 137-148

DOI: http://dx.doi.org/10.14195/1984-249X_14_10

RESUMEN: Refutaciones Sofisticas ha sido usualmente interpretado como un intento de clasificación de sofismas. Este acercamiento, sin embargo, corre el riesgo de oscurecer la dimensión de sus propias intenciones confrontativas. El presente trabajo se propone enfatizar la importancia de las Refutaciones Sofisticas como parte de un programa antierístico que tiene por objetivo prioritario la filosofía megárica, en las antípodas de Aristóteles en el terreno epistemológico. Bajo esta luz, la resolución de argumentos erísticos excede el estudio lógico así como también la denuncia sobre sus efectos prácticos y se erige como parte de una discusión entre líneas de inspiración socrática sobre los alcances y fines de la dialéctica y la filosofía en general.

Palabras claves: Dialéctica; Lógica;Megáricos;Aristóteles; Falacias

ABSTRACT: Sophistical Refutations has been usually taken as an attempt to classify sophisms. This approach, however, risks of obscuring the extent of its own confrontation all purposes. This paperaims to emphasize the importance of Sophistical Refutations as part of an antieristical program against Megarian philosophy, which was antithetical to Aristoteli an perspectives regarding epistemology. In this light, the resolution of eristical arguments exceeds logical study as well as the denunciation of their practical effects. Indeed, it is part of a discussion between groups inspired on Socrates about the scope and purpose of dialectic and philosophy in general.

KEYWORDS: Dialectic; Logic; Megarians; Aristotle; Fallacies
* Universidad de Buenos Aires - CONICET - Buenos Aires, Argentina. (claudiamarsico@gmail.com)

1. A propósito del criterio de autoconciencia disciplinar y los procesos de discusión teórica del s. IV a.C. véase el trabajo de $\mathrm{A}$. Nightingale (1995) y sobre el movimiento socrático en particular D. Clay (1994, p. 23-47) y C. Mársico (2010a).

Las estimaciones sobre su cantidad, que Rossetti calcula en más de trescientas obras (L. Rossetti, 1974-5

y L. Rossetti, 2003, pp. 11-35), y la compleja trama de autores numerosos que participan de este proceso hacen de este fenómeno un elemento que no debe ser omitido en el estudio de las dinámicas que constituyeron

el decurso teórico de la época clásica.

2. Véase Aristóteles, Poética, 2.1447a27-b11.

3, Una versión extendida de este tópico fue abordado en la introducción de nuestra traducción anotada del Eutidemo(Mársico - Inverso, 2011, p. 26-58)

\section{Claudia Mársico*}

La conformación de la filosofía como disciplina autónoma con autoconciencia de su espacio en el plexo de saberes de la época clásica tuvo lugar en los albores del s. IV a.C. en el marco de un proceso impulsado por la figura de Sócrates y su potencia inspiradora de múltiples líneas de pensamiento que conformaron el clima intelectual del tránsito de la época clásica a la helenística ${ }^{1}$. Junto al platonismo, sancionado por la tradición como pilar ineludible, constituyeron posiciones fundamentales la de los megáricos, cirenaicos y antisténicos. En todas estas corrientes la figura de Sócrates opera como pivote, como lo muestra inequívocamente el hecho de que todas adoptan el formato textual de los sokratikoilógoi, que Aristóteles no duda en considerar un género literario independiente. ${ }^{2}$ El abultado número de obras que la doxografía testimonia apoyan este juicio y sindican la práctica socrática como motor de tensiones dialógicas que configuran modelos dialécticos muy diversos y de rasgos encontrados. En este sentido, prestando atención a este contexto de discusión teórica, múltiples aspectos que la historiografía habitual suele conectar sin más con la sofística del s. V a.C. pueden ser reinterpretadas con provecho como indicio de debates entre líneas socráticas de la primera mitad del s. IV. 
Esta práctica recibió un embate pleno de beligerancia en el Eutidemo de Platón, transido de alusiones a desarrollos de la corriente megárica corporizados en personajes fastidiosos que dominan una técnica de refutación tan disparatada como peligrosa por sus efectos devastadores en el ánimo de interlocutores que no vislumbran este procedimiento como algo decididamente distinto de la dialéctica de cuño platónico. La atención al Eutidemo de Platón y su programa antierístico ha sido desde antiguo un punto ineludible para abordar las Refutaciones sofísticas de Aristóteles, si bien dicha cuestión suele quedar relegada a comentarios marginales poco decisivos ala hora de determinar la naturaleza y objetivos del texto. El presente trabajo, por el contrario, se propone enfatizar la importancia de la relación entre estas obras en tanto elementos para comprender su inserción en un programa antierístico de cuño platónico-aristotélico que denunciaba la ilegitimidad de las prácticas refutativas que apelaban a inconsecuencias lógicas.

\section{El origen socrático de la erística}

Los problemas relacionados con Refutaciones sofísticas comienzan, como pasa a menudo con obras de Aristóteles, por el título mismo: Perìtônsophistikônelénchon. Desde la antigüedad proliferaron discusiones en torno de dos aspectos principales. Por un lado, sobre la naturaleza del proyecto $y$, por otro, sobre la identidad de los sofistas aludidos. En cuanto a la primera cuestión, las alternativas exegéticas giran en torno del sentido que se atribuya al genitivo sophistikôn, ya sea que se le dé una interpretación sujetiva- refutaciones que los sofistan llevan a cabo -, con lo cual se trataría de un estudio de las estructuras argumentativas diseñadas por este grupo, o una interpretación objetiva - refutaciones contra los sofistas -, que implica impugnar la práctica de este movimiento. Los comentadores antiguos tendieron a priorizar el sentido objetivo, como se ve en Galeno y Filópono, ${ }^{4}$ más tarde se prefirió el sujetivo, y no faltaron intentos de aunar ambas posibilidades, como la del Ps. Alejandro, que sostiene que la obra encarna un proyecto de exposición de las refutaciones que usan los sofistas - sentido sujetivo - como prolegómeno a su impugnación -sentido objetivo-. Modernamente está claramente extendida la lectura sujetiva, que tiene la ventaja de enfatizar las aristas estructurales del estudio de Aristóteles respecto del entramado lógico-metodológico puesto en juego antes bien que las acciones guiadas por la animadversión orientadas a un grupo particular.

A pesar de eso, la revisión de la identidad de los sofistas no pierde importancia, precisamente porque la evaluación general del criterio con el cual se colecciona y ordena el canon de argumentos a tratar depende en buena medida del material que ofrece el grupo en cuestión. Lo primero que cabe notar es que los tradicionalmente llamados sofistas, es decir el movimiento intelectual del s. V a.C., son rara vez mencionados. La lista está restringida a la alusión de Antifonte en el \# 11, Protágoras en el \# 14, Licofrón en el \# 15 y Trasímaco y Gorgias en el \# 34. Por otra parte, en ninguna de la menciones está presente una intención adversativa que amerite suponer que la obra entera los tiene en la mira. ${ }^{6}$ Más aun, la tesis misma de que se pretende confrontarlos colisiona con el hecho de que la refutación dialéctica no parece haber sido su método principal, de modo que la supuesta oposición tomaría aspectos que son ajenos a la práctica originaria o las fuentes no han considerado pertinente conservar. Las asociaciones en esa dirección están apoyadas en fundamentos endebles. Por ejemplo, se ha apelado a la sexta definición del Sofista de Platón, en el pasaje 230a$d$, para atribuirla al movimiento general, cuando es altamente plausible que se trate de una alusión a la práctica socrática que se erigiría como una "sofística noble": así como la retórica noble se pone al servicio de la filosofía y lo mismo la poesía, así también la sofística, en su dimensión de refutación purificatoria oficiaría de auxiliar del método filosófico. ${ }^{7}$ Con esta duda en el horizonte resulta temerario definir la actividad sofística por esta mención y suponer que Refutaciones sofísticas discute con este grupo.

Al mismo tiempo, un examen de las figuras señeras del movimiento sofístico tampoco arroja resultados positivos respecto del uso de la refutación dialéctica. Podría aducirse que Protágoras, según Diógenes Laercio, 9.53, fue un antecedente
4. Véase Galeno, Sobre las opiniones de Hipócrates y Platón, V.221 y De captionibus, $1.4 \mathrm{y}$ Filópono, Sobre los Analíticos posteriores, 2.5-17.

5. Véase, por ejemplo, P. Aubenque (1962, p. 97); J. Dumont (1986, p. 195); L. Dorion (1995, p. 20-4)

6. Sobre este punto, véase Dorion (1995, p. 33), que enfatiza los inconvenientes de asociar a los tradicionalmente llamados sofistas con los efectivos interlocutores teóricos de esta obra de Aristóteles. En la línea tradicional, que da por sentado que Aristóteles se refiere a la generación de sofistas del s. V a.C. y sus continuadores de principios del s. IV a.C., véase C. Classen (1981, p. 23 ss.) y J. Poulakos (1996, p. 45 ss.).

7. Esta tesis es sostenida por G. Kerferd (1981). Con un presupuesto similar operan $\mathrm{N}$. Notomi (1999, 44 y 66) y R. Barney (2009, pp. 77-98) 
de la práctica socrática, pero esta apreciación resulta un caso aislado probablemente fundado en la interpretación de las antilogías como una actividad dialógica, cuando en rigor parecen haber sido discursos opuestos del estilo de los Dissoi logoi. Los pocos casos de asociación de Protágoras con el término erístico, como crítica dirigida a esta prácti$\mathrm{ca}$, adolecen de cierta vaguedad o anacronismo. ${ }^{8}$ En todo caso, parece no tratarse del núcleo del estilo protagórico, sobre todo si conferimos algún tipo de credibilidad a su retrato platónico en el Protágoras, donde aparece como un paladín del makròslógosy fuera de este terreno resulta un interlocutor muy poco ducho en las lides de la discusión. Si es así, este modelo estaría lejos de corresponder a la práctica del movimiento sofístico del s. V. Al contrario, como muestra este caso y revisaremos enseguida, la práctica refutatoria revela otros orígenes.

Si se procede a un recuento de alusiones en el texto de Refutaciones sofísticas, el primer plano está ocupado por los megáricos y los eleáticos Parménides, Zenón y Meliso. La conjunción entre esta persistencia y la presencia del término eristikós ha llevado a examinar la raigambre megárica del grupo primariamente aludido en Refutaciones sofísticas. ${ }^{9}$ En efecto, 'erísticos' es una denominación que se da habitualmente a este grupo, junto con 'dialécticos', y en sus desarrollos se concentran los aspectos que Aristóteles pretende desentrañar.

Al mismo tiempo, la relación megáricos-eleágoras en los megaricos (1995, p. 41), dado que la aplicación del término a este sofista es anacrónica. R. Hawtrey (1981, p. 37) afirma que el desarrollo de la erística es posterior

9. Con esta idea coinciden Hawtrey (1981, p. 29), S. Ebbese (1981, I., p. 228), R. Muller $(1988$, p. 39 y 114) y Dorion (1995, p. 47-58)

10. Véase C. Mársico (2011) y M. Gardella (2013)

11. Véase K. von Fritz (1931, p. 702-724). Esta línea sigue, po ejemplo, G. Giannanoni en su comentario a los pasajes en SSR

(1990)

12. Véase D. Hitchcock (2000 p. 59-67).

línea socrática "pura". Nos hemos dedicado en otra parte a describir los inconvenientes de esta lectura, a los cuales puede sumarse la información derivada del recorte operado en Refutaciones sofísticas por Aristóteles, que constituye una razón adicional para sostener que la línea megárica era considerada
El iniciador de la impugnación contra la tesis de un origen fusional fue sin duda K. von Fritz, que en su trabajo publicado en el Suplemento V de la Paulys Real Encyclopaedie refirió a Sócrates la práctica megárica de tipo erística y esto se interpretó como una impugnación respecto de la raigambre eleática del megarismo. ${ }^{11}$ En esta presentación, el origen del formato argumentativo se pretende inseparable de los núcleos de contenido. En rigor, este presupuesto resulta poco admisible, ya que no hay contradicción en reconocer el origen socrático de la práctica erística e identificar al mismo tiempo ciertos elementos eleáticos que operan como instrumentos conceptuales con los que se construyen argumentos concretos. La apelación a oposiciones existenciales férreas, la negación del cambio y la potencia, la imposibilidad de instaurar conocimiento respecto de lo sensible resultan elementos que atraviesan los testimonios sobre el megarismo independientes del formato argumentativo de tipo erístico en el que están codificados. Cabe decir que la sugerencia de von Fritz proyecta sobre el contenido aspectos efectivamente socráticos que encuentra en la dimensión metodológica. Sin embargo, si atendemos a trabajos como el de Hitchcock, que encuentra en Sócrates el origen de la erística, el panorama se aclara. En esta tesis el modelo de intercambio erístico que se presenta, por ejemplo, en el Eutidemo,es exactamente el método socrático de refutación, con la única diferencia estructural de que el modelo erístico avanza en el requisito de tipos fijos de respuesta, con lo cual se convierte en un método rígido. ${ }^{12}$ Estrictamente, es cierto que la fórmula de etización del ser uno parmenídeo representa poco el enfoque megárico, pero también lo hace la desvinculación respecto de la matriz eleática que vulnera, además, el modo en que la antigüedad lo comprende sistemáticamente.

\section{La práctica megárica} efectivamente una versión modificada del eleatismo.
Contando, entonces, con que Refutaciones sofísticas constituye un programa primariamente antimegárico, es preciso detenernos en un bosquejo de los lineamientos de esta vertiente teórica. En la base de la propuesta se halla una gnoseología pesimista que produce un modelo dialéctico basado 
en la refutación sistemática de toda tesis positiva y la formulación de paradojas que revelen la ambigüedad intrínseca de las nociones instrumentales fundantes del conocimiento, tales como existencia, conocimiento o verdad.

Diógenes Laercio, 2.106 (FS, 83) informa que Euclides sostenía que sólo el bien existe y “es uno, aunque se lo llame con muchos nombres: unas veces sensatez, otras divinidad, otras inteligencia". El corolario directo de esta tesis es la inconmensurabilidad entre la estructura de lo real y la estructura lingüística, de modo que no existe correlación posible entre ambas y esto arrastra irremisiblemente consigo la noción de verdad como adecuación del pensamiento a lo real. Este pesimismo, como decíamos, condiciona la práctica teórica hasta el punto de convertirla en una suerte de propaganda escéptica. Séneca dirá más tarde, sumando a los megáricos al grupo de los escépticos pirrónicos y académicos, que instauraron la nueva ciencia de no saber nada. ${ }^{13}$ Estrictamente, esta afirmación que pretende ser jocosa y descalificadora encierra una cuota de verdad si se tiene en cuenta que la vocación militante del grupo megárico parte de la imposibilidad de alcanzar conocimiento cierto, pero para ofrecer apoyo a su hipótesis desarrollaron un andamiaje importante de elementos técnicos que constituyeron un invalorable aporte a la lógica antigua. En algún sentido los megáricos construyeron una "ciencia de no saber nada" que se plasmó en un aparato metodológico apoyado en una red de paradojas prestas a derribar cualquier sistema teórico. ${ }^{14}$

Cuando nos preguntamos por este aparato metodológico emerge precisamente la dimensión erística y su motor de refutación. De Euclides se cuenta que "se oponía a las demostraciones no en las premisas (lémmata) sino en la conclusión (D.L. $2.107=$ FS, 88)". En su carácter negativo la formulación llama la atención sobre un modelo positivo en el cual las refutaciones, definidas como oposición a las demostraciones, proceden a partir de las premisas revisando la lógica de conexión con la conclusión. Esta progresión es controvertida por la propuesta de Euclides que invierte esta prioridad extractando la conclusión de su contexto de producción argumentativa. El procedimiento parece ser precisamente el que denuncia Platón en Fedón, 101e, después de insistir en la importancia de atenerse con suma cautela a un método estricto que parta de hipótesis y cuide la relación de enunciados a partir del criterio de relación con la hipótesis básica. Como corolario, se indica que no hay que enredarse "discutiendo acerca del principio mismo y lo derivado de él si es que querías encontrar algo acerca de lo real" (101e). Esta mezcla de planos, se advierte, es propia de erísticos que revuelven todo y con eso se quedan conformes. ${ }^{15}$

Es muy plausible que esto constituya una referencia a los megáricos guiados por principios metodológicos como el de Euclides, que colisionan directamente con las pautas platónicas. Euclides no aceptaría examinar enunciados para ver si concuerdan con la premisa básica, sino que precisamente para desarticular este proceder avanzaría aislando conclusiones y sometiéndolas a aparatos productores de paradojas y propiciando estructuras de modus tollens para que si la conclusión es refutada no puedan aceptarse las premisas. Para sopesar el procedimiento basta apelar al vertiginoso pasaje de Eutidemo, 293b-303a, donde en una rapsodia de argumentos los enunciados son extractados de su contexto original para adaptarlos a modelos de refutación prediseñados. Estrictamente, la direccionalidad de la dialéctica megárica es inversa a la de otras líneas, especialmente la platónico-aristotélica, y constituye un modelo tan irreconciliables como llamado a colisionar teóricamente con el resto. ${ }^{16}$ Sobre este horizonte es comprensible que en Eutidemo, el erístico aparezca bajo la figura de la hidra a la que se cortan las cabezas y sólo sale fortalecida. Del mismo modo el erístico es alimentado con argumentos de los que puede descontextuar conclusiones para reducirlas a estructuras paradójicas.

Si se requiere un muestreo más amplio de los argumentos megáricos, hay que recurrir sin duda a Eubúlides de Mileto. Discípulo de Euclides de Mégara y contemporáneo de Aristóteles, es conocido como autor de una serie de argumentos dialécticos que pasaron a la posteridad y desafían todavía hoy a la lógica. En el caso del sorites, por ejemplo, se tematiza la vaguedad de ciertos términos como 'mucho' o 'poco', de un modo que Diógenes Laercio sintetiza
13. Séneca, Cartas a Lucilio, 13 [= 88] 43-5 (FS, 87).

14. Sobre la posición megárica, véase K. Döring (1972), R. Mulle (1988), C. Mársico (2013), M. Gardella (2013).

15. Esta conexión resulta relevante, dado que esta alusión pone a los megáricos como interlocutores que refuerzan la necesidad de que Platón conforme lo que suele llamarse el "método hipotético", de modo que constituyen, a través de su crítica, motores del avance teórico del platonismo. Sobre la apelación a hipótesis véase S. Menn (2002, p. 193-223) y, en un contexto de diálogo con líneas socráticas, el punto 4.2.1 de nuestra Introducción al Hipias Menor en Mársico (2011: pp. 49-61).

16. No nos detendremos aquí en el caso del Parménides, texto que revela el formato de impugnación respecto de la teoría de las Formas que se desarrolló en terreno megárico, como muestra la versión del argumento del tercer hombre de Políxeno, hasta el punto de que toda la primera parte del Parménides puede ser entendida como un pasaje intertextual que recupera las críticas megáricas a la participación bajo el auspicio del iniciador del eleatismo. Sobre este punto, véase C. Mársico (2012) y M. Gardella (2013). 
del siguiente modo: "no es cierto que dos sea poco, pero tres no; y tampoco que éste lo sea, pero cuatro no y así hasta diez. Y dos es un número pequeño, por lo tanto diez también" (7.82 = FS, 170). En este antecedente de tratamientos caros a la lógica contemporánea, especialmente a través de la llamada fuzzylogic, que contempla diversos acercamientos a la verdad, y de las teorías de la supervaluación, que apelan a tres valores veritativos, Eubúlides llamó la atención sobre la imposibilidad de determinar, en este caso, la noción de montón, punto del cual se infiere la equivocidad de la información de los sentidos, de modo que, como dice Aspasio, "ninguna de las cosas sensibles se capta con precisión, sino en general y de modo aproximado". ${ }^{17}$

En el caso del Cornudo -“lo que no has perdido, lo tienes; tú no has perdido los cuernos, entonces tienes cuernos"-, ${ }^{18}$ Eubúlides pone en juego la duda sobre la eficacia de la deducción, que en este caso podría llevar a colegir la existencia de algo que de ningún modo existe, que en el ejemplo son los cuernos. La perspectiva general que surge del análisis de los argumentos atribuidos a Eubúlides muestra que el plano lingüístico precipita inevitablemente en el error, dado que propone al entendimiento términos que, en rigor, no tienen significación unívoca. Un refugio en los lógoi, como proponía Platón en Fedón, 99d, para un megárico no tiene sentido más que como parte de un programa de purificación epistemológica y para mostrar que el lenguaje es intrínsecamente contradictorio y por lo tanto, lejos de ser una vía para la dialéctica, es una tela de araña en la que perece todo intento de alcanzar lo real.

Además del catálogo de paradojas, Eubúlides interesa a nuestro trabajo porque sostuvo una polémica tanto teórica como personal con Aristóteles. El enfoque erístico de su pensamiento se proyecta en la lista de paradojas, pero también en el material biográfico, donde se lo sindica como maestro de Demóstenes y responsable de haberlo librado de defectos de dicción. ${ }^{19}$ A propósito de ello se dice que "con argumentos falaces enredaba a los oradores". Aunque entrenados en el discurso expositivo, los expertos en retórica quedaban en manos del andamiaje de paradojas apoyadas en interrogatorios dialécticos, lo cual es un indicio adicional de la distancia entre el modelo de orador sofista y el de erística socrática. En efecto, Diógenes Laercio testimonia que Eubúlides “estaba en desacuerdo con Aristóteles y lo ha atacado con vehemencia en muchas oportunidades". El origen del enfrentamiento nos es desconocido y sólo podemos colegir los efectos escandalosos en el testimonio de Aristocles, que acusa a Eubúlides de mentiroso porque atribuía a Aristóteles "poemas fríos, aunque los han compuesto otros, acerca del matrimonio y el parentesco que tenía con Hermias, y luego pretendiendo que Aristóteles ofendió a Filipo, no estuvo junto a Platón cuando murió y destruyó sus obras". ${ }^{21}$

Como es claro, los motivos aducidos eluden la cuestión teórica. Sin embargo, las obras aristotélicas ofrecen ejemplos de críticas a los megáricos que seguramente fueron parte de la cuestión. Sin ir más lejos, la discusión sobre la potencia de Metafísica 9, dirigida contra los megáricos en general, abre el problema de identificar a sus interlocutores específicos. No han faltado autores que creen ver esta figura en Eubúlides o en Diodoro Crono. ${ }^{22}$ En perspectiva, sin embargo, la disidencia con Eubúlides no parece basarse en el terreno metafísico sino en el metodológico. Dado que sus desarrollos principales pertenecen al terreno del diseño de argumentos, es claro que una obra como Refutaciones sofisticas, orientada a descubrir e impugnar esa lógica de producción tiene que haber opuesto tajantemente a estos autores.

Euclides y Eubúlides constituyen, entonces, la permanencia generacional megárica que oficia de correlato de la línea tendida entre Platón y Aristóteles y se erigen como protagonistas centrales de la zona de tensión dialógica asociada con el método adecuado para la filosofía. En efecto, más allá de las noticias sobre la polémica entre Aristóteles y Eubúlides, interesa notar que esta fricción teórica tiene su antecedente directo en la que se dio en la generación previa, para lo cual podemos remitirnos a los desarrollos del Eutidemo a los efectos de poder definir la relación que entabla este texto con Refutaciones sofísticas, en tanto representantes de un persistente programa antimegárico. En efecto, así como RS, el Eutidemo ha sido entendido en diálogo 
polémico con los megáricos. ${ }^{23}$ Muller, por ejemplo, no deja de notar que Euclides estuvo activo desde antes de la fundación de la Academia y murió cerca del comienzo del período de vejez, de manera que Platón tenía como modelo los desarrollos megáricos que estarían en el horizonte de las posiciones con las que discute. ${ }^{24}$ El corpus íntegro resulta así no sólo una exposición de su pensamiento sino también una toma de distancia respecto de otras versiones de la dialéctica. En lo que sigue nos internaremos en ciertos aspectos puntuales de este clima de discusión.

\section{La paradoja del aprendizaje, las falacias paràtènléxin y el caso de la composición}

Varios argumentos del Eutidemo vuelven a aparecer en Refutaciones sofisticas, punto que ha dividido a los intérpretes en torno de la relación entre ambos diálogos. Si la tesis de continuidad entre obras ha sido la respuesta más general, no ha faltado la denuncia de inconmensurabilidad entre los dos enfoques. El mayor problema está constituido por el diagnóstico en términos de "deuda". En efecto, la tendencia a las lecturas internas ha priorizado exégesis en las cuales la repetición de una temática sólo puede explicarse por adopción directa, dejando de lado la posibilidad de que tal coincidencia responda a la integración de ambos textos en un plexo mayor. Desde nuestra perspectiva, tanto las coincidencias como las diferencias entre Eutidemo y Refutaciones sofísticas se explican si analizamos la conformación de la zona de tensión dialógica en la cual están insertos y el modo que cada uno tiene para posicionarse dentro de ella. En este sentido, junto a las propuestas de Platón y Aristóteles ocupa un lugar prioritario la línea megárica a la que ambos se oponen en el terreno epistemológico.

El capítulo 4 de RS presenta la refutación como actividad sofística y propone la división entre elenchosparàtènléxin y exoteslexeos para examinar luego los tipos que conforman el primer grupo: homonimia, amfibolía, forma de la expresión, división, composición y acentuación. Como ejemplo de homonimia se ofrece la paradoja del aprendizaje de Euthd., $275 d-277 c$, como ejemplo de amfibolía aparece la imposibilidad de mentir de Euthd., 283e-284a y los ejemplos de las cosas que ven de Euthd., 300a-b y como caso de composición aparece el sofisma del changarín del que se ha visto un antecedente en Euthd., 296a-c. Fuera del capítulo 5, en el marco de las refutaciones fuera de la expresión se ofrece la falacia de accidente de Euthd., 298a-b y en el capítulo 24 , donde se muestran soluciones a las falacias de accidente, encontramos el argumento del perro de Euthd., 298e. Como se ve, los argumentos del Eutidemo se concentran en el ámbito de las equivocidades lingüísticas y las falacias de accidente.

El primer caso corresponde a la conocida paradoja del conocimiento que Platón plantea en dos formulaciones: si los que aprenden son los que saben o los que no saben y si los que aprenden aprenden lo que saben o lo que no saben. En ambos casos la ambigüedad entre los dos sentidos de manthánein, 'comprender' y 'aprender' aseguran que quien logre instalar el diálogo en este punto tenga asegurada la refutación del interlocutor y logre aquello de lo que se ufana Dionisodoro en Euthd., 275d: "conteste lo que conteste será refutado". En términos de la metodología euclidea, la tarea del interrogador consiste en aislar un enunciado que se adapte a la estructura de un argumento refutativo. Así, en el primer caso, si se contesta que manthánei el que sabe se aducirá el sentido de aprender que es temporalmente prospectivo, y si se contesta que manthánei el que no sabe se aducirá el sentido de comprender que es temporalmente resultativo. Así, a quien diga que aprenden los que no saben se le dirá que si no acceden al manthánein en su sentido de comprensión no pueden aprender, por lo tanto aprenden los que saben, y a quien diga que aprenden los que saben se le dirá que el que sabe tiene ya en su poder el conocimiento en cuestión y por tanto no aprende.

Aristóteles presenta dos alusiones a este argumento que tomaremos como ejemplo o clave para ahondar en la lógica que subyace a la clasificación de RS, 4. En la primera alusión se adopta la primera formulación del Eutidemo para instalarla como ejemplo de falacia de homonimia y se aclara la diferencia de sentido entre comprender y adquirir un conocimiento (RS, 4.165b31-4). La segunda, en
23. A. Rüstow (1910, p. 35-9); Hawtrey (1981, p. 30), M. Canto (1989, p. 28), Dorion (1995, p. 49), C. Mársico- H. Inverso (2012, Introd.).

24. Muller (1988, p. 122). 
25. Lo mismo notan correctamente W. Parry - E. Hacker (1991, pp. 428 ss.) y S. Schreiber (2003, p. 55). Sobre la concepción contemporánea que subyace al equívoco, véase $F$. Van Eemeren et al. (2009, p. 18). S. Ebbesen (1981, p. 78 ss.) remonta al Per tôn parà tèn léxin sophismáton de Galeno, el trabajo post-aristotélico más antiguo que conservamos, la serie de malentendidos posteriores.

26. Véase W. Kneale- M. Kneale (1962, p. 93). La explicación sobre la base de la diferencia entre posibilidad absoluta y relativa es expresamente descartada por Aristóteles en RS, 20.177b22-5 166a30-1, es mucho más compleja y ha producido una importante cantidad de variables interpretativas y propuestas de alteración del texto que nos lleva al complicado terreno de las falacias de composición y división, terreno especialmente apto para sopesar las similitudes y diferencias de los enfoques de Platón y Aristóteles.

Cabe notar que es preciso evitar un malentendido extendido, que vicia, por ejemplo, la interpretación de M. Canto: las falacias de composición y división tal como las plantea Aristóteles nada tienen que ver con las proyecciones indebidas de la parte al todo y del todo a la parte que integran los catálogos modernos de falacias. ${ }^{25}$ Estrictamente, si se tratara de una relación partes-todo este patrón de falacias no debería estar en el grupo fundado en el lenguaje. Al contrario, la lógica general de este conjunto es que la equivocidad es un efecto lingüístico. En el ejemplo que nos ocupa, como veremos, las letras (grammata) son partes de un todo, pero este rasgo no afecta el aspecto por el cual se considera que hay un caso de composición. Al mismo tiempo hay que descartar la interpretación de los Kneale, que ven en estos ejemplos una ambigüedad derivada de la confusión entre usos de posibilidad en sentido absoluto y en sentido relativo, es decir con cierto condicionamiento témporo-contextual. ${ }^{26}$ Nótese que también en este caso se estaría confundiendo la composición con la homonimia, ya que la falacia se apoyaría en un doble sentido del verbo dynásthai. Sin embargo, como nota Schreiber, estrictamente en ese caso no existe doble sentido sino un caso de falacia extramental del tipo secundum quid que alejaría totalmente la explicación de la lógica de los argumentos paratenlexin.

Prestando atención a este contexto, entonces, es importante no confundir la lógica que guía a Aristóteles a incorporar el tratamiento de la paradoja del conocimiento entre las falacias de composición, ya que separa claramente los argumentos referidos al lenguaje en dos grupos colocando por un lado la homonimia y la amfibolía y por otro las falacias de composición, división y acento. Si se supone, como hace Dorion, que la formulación de 166a30-1 que se ofrece como caso de composición corresponde a un modelo similar al que oficia de ejemplo de homonimia, la diferencia establecida entre los dos grupos de falacias pierde sentido. Al contrario, es preciso colegir qué rasgo se atribuye a este argumento que justifique su rasgo compositivo.

Revisemos sumariamente el concierto de ejemplos de composición:

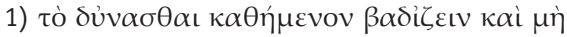

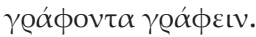

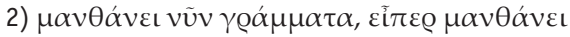

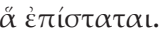

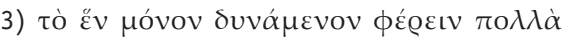

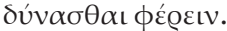

Los ejemplos de (1) y (3) se apoyan en las diferentes interpretaciones adverbiales que puede recibir un participio griego, que van desde lo concesivo - es posible caminar aunque se esté sentado, y es posible escribir aunque no se esté escribiendo - a lo temporal - es posible caminar mientras se está sentado, es posible escribir mientras no se está escribiendo. Es claro que no se trata aquí de una cuestión de amfibolía como la de los acusativos sujetivo y objetivo en proposiciones objetivas del tipo

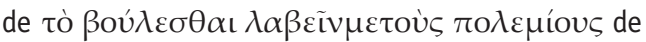
166a8, cláusula que puede significar tanto "querer que yo capture a los enemigos" como "querer que los enemigos me capturen", básicamente porque la equivocidad no parte de una determinada construcción sintáctica sino de la dimensión semántica de un tipo léxico concreto, en este caso el participio. Estrictamente no hay posibilidad de más de una interpretación sintáctica como en la amfibolía, ni más de una interpretación semántica como en la homonimia, sino lexemas o sintagmas ajenos a la estructura básica de la cláusula que en determinados contextos pueden hacer surgir problemas de interpretación. Podemos decir, en términos de lingüística moderna, que dado el ensamble de un núcleo verbal con sus argumentos externo (sujeto) e interno (constituyentes del predicado dictados por la selección del verbo en cuestión), la falacia de composición se produce cuando un constituyente en carácter de adjunto se adosa a la cláusula básica produciendo un efecto de sentido contradictorio o potencialmente equívoco. La diferencia con la amfibolía, entonces, radica en que mientras la primera 
opera sobre constituyentes básicos, la composición y la división recurren a los efectos que surgen de la combinación entre argumentos y adjuntos.

Con una estrategia diferente, Schreiber radicaliza la distancia con la amfibolía para acercar la estructura de la composición y la división a la falacia de acentuación suponiendo que este tipo de efectos son propios de la transcripción escrita que tenía a su disposición en esta época un aparato de signos diacríticos deficiente y por tanto creaba amplias zonas de indefinición que propiciaban errores. ${ }^{27}$ Sin embargo, el ejemplo de la paradoja del conocimiento que nos convoca muestra que no se trata de una vía de análisis fructífera. Si este tipo de argumentos funcionaba en el Eutidemo y en general dentro de la práctica megárica es porque también en la versión oral era posible mantener la indefinición. Es claro que muchos de los equívocos desaparecen con la reposición de un contexto adecuado y con la materialización que muestra la intencionalidad del hablante, ya que de lo contrario la lengua misma rechazaría construcciones ininterpretables, y eso se da más naturalmente en el discurso oral. Sin embargo, como todas las falacias, se trata de casos que avanzan en los márgenes y manteniendo una neutralidad tal, incluso en el discurso oral, como para hacer emerger la equivocidad. En todo caso, la mención de la oralidad sirve para enfatizar que no se trata, como en la homonimia y la amfibolía, de casos de doble sentido - de un término o de un enunciado respectivamente -, sino de efectos de ciertas operaciones sobre un enunciado para propiciar una cierta distribución léxica, de manera que la acción sofística consiste en estos casos en sugerir una interpretación sintáctica para deslizarla luego hacia otra.

Schreiber reivindica como ejemplo de la raigambre oral de este patrón argumental el caso de RS, 20.177b14-5, donde Aristóteles alude a la conocida crítica a Simón el zapatero, integrante del círculo socrático, según la cual era tan buen hombre como mal zapatero. El enunciado plantea lo siguiente:

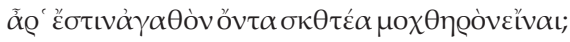

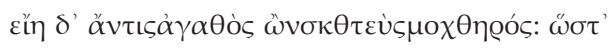

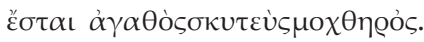

¿Acaso es posible que siendo bueno sea un zapatero malo? Alguien que es bueno podría ser un mal zapatero, de modo que será un buen zapatero malo.

A primera vista, de nuevo, parece no haber diferencias entre este caso y los de amfibolía, ya que la oscuridad de $\dot{\alpha} \gamma \alpha \theta$ ò $\varsigma \kappa v \tau \varepsilon \dot{s} \varsigma \mu \chi \chi \theta \eta \varrho o ́ s p a r e c e$ venir simplemente de la imposible identificación del predicativo sujetivo sin apelar al contexto. Sin embargo, si se presta atención a la introducción del argumento, que es donde efectivamente de plasma la composición, encontramos de nuevo un sintagma de participio, $\grave{\alpha} \gamma \alpha \theta$ òv óv $\alpha \alpha$, cumpliendo una función similar a los ejemplos del capítulo 4, de modo que el ejemplo debe resolverse del mismo modo afirmando que la composición adviene cuando un constituyente sintáctico ajeno a la cláusula básica se adopta con un valor adverbial que colisiona con el sentido de la cláusula en cuestión.

El argumento del changarín que figura en ejemplo de (3) debe ser resuelto de la misma ma-

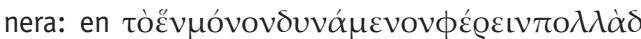

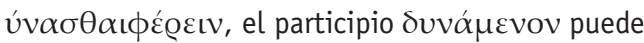
formar un núcleo modal que selecciona el infinitivo

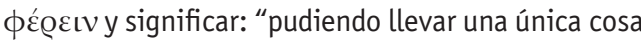
se puede llevar muchas" o seleccionar uóvov y significar "pudiendo solamente llevar una cosa se puede llevar muchas" o construirse con $\phi \varepsilon ́ \varrho \varepsilon เ v \pi \mathrm{O} \lambda \lambda \dot{\alpha}$ y significar "pudiendo llevar muchas cosas se puede llevar una sola". ${ }^{28}$ Todas las variantes surgen de un núcleo léxico que abre lecturas diversas dando lugar a enunciados de contenido diferente. En general, la exégesis de este ejemplo se complica por la

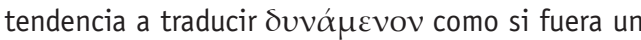
participio sustantivado que funcionaría como núcleo del sujeto, lo cual aniquila el fenómeno mismo de la composición, ya que no queda en ese caso constituyente potencialmente separable sin riesgo de colapso para la frase. Al contrario, como se ve en (1), el artículo cumple una función meramente

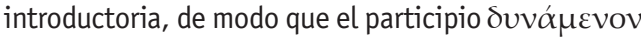
tiene pleno valor adverbial.

Este argumento forma parte del concierto de pasajes que se ha sindicado como paralelo a los de Eutidemo. En efecto, la transición de llevar una cosa a llevar muchas se ha comparado de manera abundante con el argumento por el cual Eutidemo y
27. Véase S. Schreiber (2003, p. 61).

28. Nótese que $S$. Schreiber (2003, p. 67) toma en cuenta las dos primeras posibilidades $\mathrm{y}$ L. Dorion (1995, p. 95-96) sólo la segunda y la tercera. J. Tricot (1950, p. 11) traduce según la primera y G. Colli (1955, p. 652) de acuerdo con la segunda. 
Dionisodoropretenden saber todo, que parte precisamente de que si se sabe una cosa se saben todas. La progresión argumental es la siguiente: conoces algo; conoces lo que conoces por algo; siempre conoces por eso; conoces por eso todas las cosas; entonces conoces todas las cosas. La similitud con la mención de RS se ve en el pasaje siguiente:

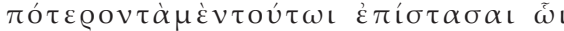

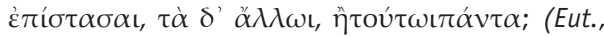
296b)

¿Acaso conoces unas cosas con eso con lo cual conoces y otras con otra cosa o todas las cosas con eso?

Estructuralmente este planteo no coincide con 29. Véase L. Dorion (1995, p. 95) 30. Véase la nota explicativa de $\mathrm{J}$. Tricot (1950, p. 11)

el de RS, como nota Dorion, ${ }^{29}$ ya que el ejemplo del Eutidemo corresponde al tipo de falacia secundum quid, mientras el de RS es lingüístico. En rigor, podría decirse que el planteo puede no ser reducido necesariamente o de modo exclusivo al argumento secundum quid, ya que el peso no está en el paso de uno a todo, que lleva a Tricot a confundir este ejemplo de composición con un sorites, ${ }^{30}$ sino, por el contrario, en la doble interpretación que surge de un enunciado a partir del complemento instrumental en dativo. Es posible ver un aspecto de este argumento enrolado en la falacia de composición porque la presencia del dativo instrumental, en tanto constituyente del nivel de adjunto, habilita la confusión en la interpretación.

En cualquier caso y aun concediendo que estructuralmente el argumento del changarín de RS no coincide con la paradoja del conocimiento universal del Eutidemo, lo cierto es que comparten un marco general llamativo, ya que la paradoja del conocimiento universal es la ocasión para que Sócrates se resista a dar respuestas por sí o por no, como muestra la escaramuza de 295b-d:

$-_{¿} Y$ conoces precisamente por aquello por lo cual eres conocedor o por otra cosa?

-Por aquello por lo cual soy conocedor. Creo, sin duda, que te refieres al alma. ¿0 no te refieres a eso?

- ¿No te da vergüenza, Sócrates? -dijo-. ¿Cuando se te interroga, repreguntas?

-Está bien -respondí yo-, pero ¿cómo hago? Porque voy a hacer como tú ordenes. Cuando no sé lo que estás preguntando, ¿me ordenas, no obstante, que responda, sin pedir aclaración?

- ¿Entiendes, por cierto, algo de lo que estoy diciendo? -preguntó-.

-Sí -respondí yo-.

-Entonces responde lo que entiendes en relación con eso.

-¿Entonces qué? -dije-. Si tú preguntas algo pensando en una cosa, pero yo entiendo otra, y luego respondo en relación con eso, ¿te basta si respondo algo que nada tenga que ver con el asunto?

-A mí sí-dijo él-, pero no a ti, según creo.

-En efecto, ;por Zeus!, no voy a responder-dije yo-, hasta que primero averigüe.

-No vas a responder -dijo- respecto de lo que entiendes siempre, porque te entregas a divagues y eres más viejo de lo debido.

Yo me di cuenta de que se irritó conmigo, que me detenía en detalles acerca de lo dicho, porque quería cazarme rodeándome con palabras.

Esto nos coloca, precisamente, en un clima anticompositivo por excelencia, lo cual puede ser indicio de que el formato erístico estaba asociado con elementos complejos dispuestos para pasar inadvertidos.

Volvamos al caso (2), a propósito de la paradoja del aprendizaje. Este caso es el único que no presenta elementos participiales, pero sí un elemento foráneo camuflado en la cláusula que provoca dos interpretaciones diferentes. Interesa aquí resaltar el paralelismo aludido por Cantó entre este pasaje y el de la segunda formulación del Eutidemo:

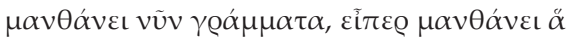

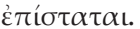

comprende ya las letras, si es que comprende lo que sabe. (RS, 4)

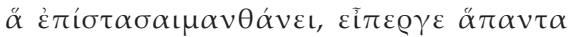
$\tau \dot{\alpha} \gamma \varrho \alpha \dot{\alpha} \mu \mu \alpha \tau \alpha \dot{\varepsilon} \pi i ́ \sigma \tau \alpha \sigma \alpha \mathrm{t}$.

comprendes lo que sabes, si es que sabes todas las letras. (Eut., 277a-b)

Como se ve, Eutidemo ofrece la frase inversa y carece de indicación temporal a través del adverbiovũv.La aclaración del pasaje de RS a través 
del paralelismo con Eutidemo fue contestada por Dorion, que rechazó la homologación con la segunda fórmula para decir que la alteración de orden implica una diferencia insalvable, especialmente porque la interpretación de Cantó atribuye a Aristóteles, como mencionamos, un tratamiento de la relación entre el todo y las partes que efectivamente está ausente del tratamiento de RS, 4. Sin embargo, no resulta adecuado descartar sin más el paralelismo para sugerir una supuesta ruptura entre ambas obras. Por el contrario, suponiendo precisamente que el Eutidemo fue para Aristóteles un elemento adicional conjugado con la producción megárica misma, nada indica que la falta de una identidad completa de planteos quiebre la pertenencia de ambos a una misma zona de tensión dialógica. Partiendo de este presupuesto podemos reexaminar los planteos inversos de la segunda formulación de la paradoja del aprendizaje y resolver su relación y el modo en que Aristóteles considera lícito incluirla entre las falacias de composición.

En el planteo de Eutidemo, la respuesta a la pregunta por quiénes aprenden es que aprenden los que no saben y Eutidemo procede a introducir el conocimiento de las letras para indicar que éstas son el material de toda enunciación, de manera que cada vez que se dice algo se recurre a ellas y si ya se las conoce no se aprende lo que no se sabe sino algo ya conocido, precisamente por su estructura fonológica. Ahora bien, el elemento resultativo de esta vertiente del argumento hace que la relación entre comprender las letras y comprender lo que se sabe no sea condicional sino bicondicional. En efecto, si se comprenden los elementos básicos se comprende el plexo general y si se comprende el plexo general es que ya se está en posesión del conocimiento de los elementos básicos lo cual justifica, de paso, que la formulación se refiera

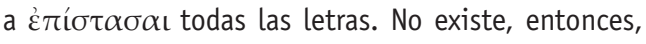
la incompatibilidad que denuncia Dorion y no hace falta reducir este caso de RS a la primera formulación del Eutidemo, diciendo que sólo puede apelarse a la

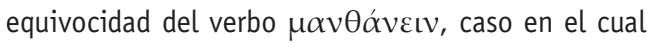
se comprendería bien poco por qué un argumento que se usa como ejemplo de homonimia podría servir a la vez como caso de composición.

Queda por ver en dónde radica la "síntesis" que cimenta la inclusión de este ejemplo en el tercer grupo de argumentos. Siguiendo el criterio que usamos en los casos previos, debe haber una cláusula básica cuyo sentido resulta alterado con el agregado de un constituyente en calidad de adjunto. La construcción condicional cumple precisamente esta función, de modo que Aristóteles estaría apuntando a la modificación operada por la introducción de una cláusula que cambia las condiciones de intelección del conjunto. En el ejemplo de RS, la condición de comprensión de lo que se sabe traslada la noción de manejo de la lectoescritura a un terreno distinto, proclive, además, a la construcción de una refutación. En este sentido, sin este agregado compositivo no hay posibilidad de diseño de la paradoja del conocimiento.

Esto nos permite remitirnos a un pasaje platónico paralelo donde las nociones asociadas con el conocimiento son puestas en cuestión. Nos referimos a la paradoja del aprendizaje de Menon, a la que alude también Aristóteles en el primer capítulo de los Segundos analíticos:

¿de qué manera vas a investigar algo que no sabes en absoluto qué es? Pues, ¿entre las cosas que no conoces, cuál te propondrás investigar? Además, aunque la encontraras por absoluta casualidad, ¿cómo sabrás que es eso que tú no conoces? (80d).

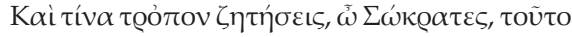

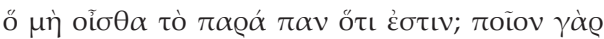

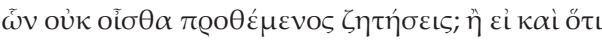

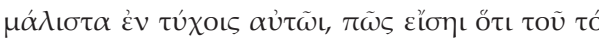

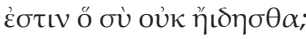

Los aspectos problemáticos de esta cuestión son completados por el mismo Sócrates que agrega, en la misma línea que el Eutidemo, que no se puede

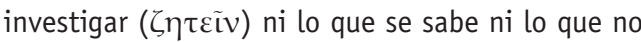
se sabe: no se investiga lo que sabe porque ya se posee el conocimiento en cuestión y por tanto no se requiere ninguna investigación, ni lo que no se sabe, pues no se sabe lo que se busca y no se lo podría reconocer (80e). La formulación de Menón comienza por la opción negativa, que está construida apelando a la composición. Allí, a la pregunta "cuál cosa te propones investigar" se le agrega una cláusula 
“entre las que no sabes" que será la condición para que funcione la paradoja, lo cual nos colocaría, en términos aristotélicos, en un terreno compositivo.

\section{La confrontación entre modelos dialécticos de origen socrático}

El recorrido que propusimos pretende mostrar el entramado teórico que conecta el Eutidemo, las Refutaciones sofisticas y los testimonios que conservamos sobre la línea megárica según coordenadas que se apartan del juicio tradicional en términos de deuda. Una reevaluación completa de los contactos entre estas obras requiere ampliar el horizonte de textos y avanzar en la reconstrucción del entorno de tensiones dialógicas. Si Platón dispuso en el Eutidemo un concierto de tesis antimegáricas orientadas a mostrar los defectos del enfoque enfatizando sus defectos de instauración teórica y sus efectos disruptores, Aristóteles diseñó un andamiaje de críticas orientado a sistematizar vicios estructurales.

Este recorrido permite trazar el mapa básico de tensiones entre las líneas megárica, platónica y aristotélica que han dejado rastros marcados en los textos conservados. Con esta perspectiva Refutaciones sofisticas no puede ser abordado desde la oposición continuidad o ruptura con el Eutidemo. En la primera opción quedan inexplicadas no sólo las diferencias en el planteo de argumentos, sino también el impacto de las estrategias generales de abordaje sobre los pasajes concretos, mientras que en la segunda se minimizan las coincidencias, objetivos y antagonistas compartidos, clausurando una exégesis que integre estos aspectos. Una atención a los pasajes en relación con los testimonios megáricos revela una dimensión adicional en la que Refutaciones sofísticas no continúa ni rompe con el Eutidemo, sino que ofrece una estrategia alternativa de impugnación de los efectos disruptores de la práctica erística basada en el análisis estructural de sofismas.

Desde esta perspectiva, Refutaciones sofisticas constituye un programa superador que intenta evitar toda confusión entre erística y dialéctica, del tipo de la que impregna, por ejemplo, la reacción del crítico anónimo del final del Eutidemo, impugnando la primera a través de procedimientos estrictamente lógicos. La versión aristotélica se enmarca, entonces, en una suerte de dispositivo de redefinición de la dialéctica y sus relaciones con la erística, en tanto posición que sostiene una función positiva en la consecución de conocimiento frente a las líneas rivales que enfatizan los límites insalvables de las capacidades cognitivas humanas. La colisión con el grupo megárico resulta, de este modo, un estímulo directo para el diseño de la noción de método que opera en la posición aristotélica y resulta de inestimable interés para comprender a través de sus estrategias de enfrentamiento los aspectos que la unen y los que la distancian de su antecedente platónico.

\section{Bibliografia}

AUBENQUE, P. (1962)Le problème de l'êtrechezAristote. Essai Sur la problematique aristotélicienne. Paris, PressesUniversitaires de France.

BARNEY, R. (2009) “Thesophisticmovement", en M. L. Gill - P. Pellegrin (Eds.), A Companion to Ancient Philosophy. 0xford, Blackwell.

CANTO, M. (1989) L'intrigue philosophique. Essai sur l' Euthydème de Platon. Paris, Les BellesLettres.

CLASSEN, C. (1981) "Aristotle's Picture of theSophists", en G. Kerferd (ed.), The Sophists and Their Legacy. Wiesbaden, Franz Steiner Verlag.

CLAY, D. (1994) "The Origins of the Platonic Dialogue", en P. Vander Waerdt (ed.), The Socratic Movement. Ithaca-New York, Cornell University Press.

COLLI, G. (1955) Aristotele, Organon. Torino, Einaudi.

DUMONT, J. (1986)Introduction à la méthoded'Aristote. Paris, Vrin.

DÖRING, K. (1972)Die Megariker: kommentiertesammlung der testimonien.Amsterdam, Grüner.

DORION, L. (1995) Les réfutations sophistiques, introduction, traduction et commentaire. Paris, Vrin.

DÜRING, I. (1957) Aristotle and the Ancient Biographical Tradicion. Stockholm, Göteborg.

EBBESEN, S. (1981) Commentators and Commentaries On Aristotle's Sophistici Elenchi. A Study of Post-Aristotelian Ancient and Medieval Writingson Fallacies. Volume I: The Greek Tradition. Leiden, Brill.

GARDELLA, M. (2013) Las críticas de los filósofos megáricos a la ontología platónica, ms. (Tesis Lic. FFYL - UBA).

GIANNANONI, G. (1990) Socratis et socratico rum reliquiae. Napoli, Bibliopolis (SSR). 
HANFLING, 0. (2001) Whatiswrongwith sorites arguments? Analysis, Chicago, v. 61 pp. 29-35.

HAWTREY, R. (1981) Commentary on Plato's Euthydemus. Philadelphia, American Philosophical Society.

HITCHCOCK, D. (2000) "Theorigin of professionaleristic", T. Robinson - L. Brisson (eds.), Proceedings of the $\mathrm{V}$ Symposium Platonicum, Sankt Augustin, Academia. Keefe, R. - Smith, P. (eds.) (1997) Vagueness: A Reader. Cambridge-MA, The M.I.T. Press.

KERFERD, G. (1981) The Sophistic Movement. Cambridge, CUP.

KNEALE, W.; KNEALE, M. (1962) Thedevelopment of Logic. Oxford, OUP.

MÁRSIC0, C. (2010a) "Sócrates, Palamedes y otros malentendidos en torno del diálogo socrático como género discursivo", en las Actas de lasV Jornadas Nacionales "La(s) retórica(s) en la antigüedad y sus proyecciones. Persuasión y comunicación, del mundo antiguo a las prácticas contemporáneas, Rosario. Universidad Nacional de Rosario.

MÁRSIC0, C. (2010b) Zonas de tensión dialógica. Perspectivas para la didáctica de la filosofía antigua, Colección dirigida por Alejandro Cerletti. Buenos Aires, Ediciones del Zorzal.

. (2011) “Megaric philosophy: between Socrates' stamp and theghost of Parmenides", en N. Cordero (ed.), Parmenides, venerable and awe some. California, Parmenides Publishing.

.(2012) “'Ni el hombre es blanco ni el caballo corre'. Argumentos antiplatónicos en Estilpón de Mégara", Méthexis, 25.

.(2013) Filósofos socráticos, Testimonios y fragmentos. I. Megáricos y cirenaicos. Buenos Aires, Losada.

MÁRSICO, C.;INVERSO, H. (2012) Platón, Eutidemo, introducción, traducción y notas.Buenos Aires, Losada.

MARZOCCA, P. (2010a) “Diodoro Crono, Aristóteles y el problema de la potencia", Actas del XV Congreso Nacional de Filosofía - AFRA. Buenos Aires, EDUNTREF.

.(2010b) "Las nociones de acto y potencia a la luz de la polémica con Diodoro Crono", en C. Mársico (ed.), Legalidad cósmica y legalidad humana en el pensamiento clásico. Buenos Aires, UNSAMEdita.

MENN, S. (2002) Plato and theMethod of Analysis. Phronesis, 47.3, pp. 193-223.
MOLINE, J. (1969) Aristotle, Eubulides and the Sorites. Mind, 78, pp. 393-407.

MULLER, R. (1988) Introduction a la pensee desmegariques. Paris-Bruxelles, Vrin-Ousia.

NIGHTINGALE, A. (1995) Genres in dialogue. Cambridge, CUP.

NOTOMI, N. (1999) TheUnity of Plato'sSophist: Between the Sophist and the Philosopher. Cambridge, CUP.

PARRY, W.;HACKER, E. (1991) Aristotelian Logic. Newy York, SUNY Press.

POULAKOS, J. "Extending and Correcting the Rheotrical Tradition: Aristotle's Perception of theSophists", en C. Lyle Johnstone (ed.), Theory, text, context: issues in Greelrhtoric and oratory. New York, SUNY, 1996.

PRIEST, G. (2002) The Hooded Man. Journal of Philosophical Logic, 31, pp. 445-467.

ROSSETTI, L. (1974-5) Allari cercadeilogoiso kratikoi perduti (I-III). Rivista di Studi Classici [Torino] XXII-III

(2003) Le dialogue socratiquein statu nascendi.

Philosophie Antique 1, pp. 11-35.

RÜSTOW, A. (1910) Der Lügner. Theorie, Geschichteund Auflösung. Leipzig, Teubner, p. 35-9.

SCHREIBER, S. (2003)Aristotleon False Reasoning: Language and the World in the Sophistical Refutations. Albany, SUNY Press.

SEUREN, P. (2005) Eubulides as a 20th-century semanticist. Language Sciences, 27, pp. 75-95.

SORENSEN, R. (2003) "Eubulides and thePolitics of the Liar", en A BriefHistory of theParadox: Philosophy and the Labyrinths of the Mind. Oxford, OUP.

TRICOT, J. (1950) Aristote, Organon. Paris, Les Belles Lettres.

VAN EEMEREN, F. et al. (2009) Fallacies and Judgements of Reasonableness: Empirical Reasearch Concerning the Pragma-Dialectical Discussion Rules. New York, Springer.

VON FRITZ, K. (1931) Megariker. Realencyclopädie der klassischen Altertumswisseschaft. Supl. 5, 702-24. Stuttgart, Druckenmüller.

WILLIAMSON, T. (2002) Vagueness. New York, Routledge.

Recebido em fevereiro de 2014, aprovado em outubro de 2014. 